\title{
Esteve Pardo, José. El pensamiento antiparlamentario y la formación del Derecho Público en Europa. Madrid: Marcial Pons, 2020 (2ª edición).
}

\author{
Víctor Méndez Baiges \\ Departamento de Ciencia Política, Derecho Constitucional y Filosofía del Derecho \\ Universitat de Barcelona
}

Fecha de recepción 26/12/2020 I De publicación: 24/06/2021

Ha habido prácticamente unanimidad a la hora de recibir de manera calurosa al libro El pensamiento antiparlamentario y la formación del Derecho Público en Europa, el cual, tras la primera edición de 2019, ha conocido una segunda en 2020. En esta última, el autor, catedrático de Derecho Administrativo de la Universidad de Barcelona, ha añadido un epílogo donde toma nota de la cierta insistencia de dicha recepción en resaltar la similitud entre la situación política y social de la que trata su obra -la de la Europa continental de entreguerras- y aquella en la que actualmente nos encontramos.

Para muchos, el libro de Esteve nos habría proporcionado una especie de espejo. De acuerdo con ellos, si, durante la II Guerra Mundial y gracias a Thomas Mann, pudo existir un "Weimar by the sea" en las proximidades de Los Ángeles, ahora estaríamos, con la colaboración de todos, ante algo parecido a un Weimar con coronavirus.

¿Es esto así? ¿Es este el valor del libro? ¿La crisis en la que se encuentran nuestras instituciones políticas es, de alguna manera, un regreso a aquella crisis del parlamentarismo?

No me parece a mí que esto esté tan claro. En realidad, y más allá de que siempre sea posible reconocerse en un pasado en apuros, lo que hace este libro no es en absoluto hablar del presente. De lo que trata es de acontecimientos ocurridos hace ahora aproximadamente un siglo. Y la particularidad del tratamiento que les da es que, en él, el énfasis recae en la relevancia que tuvo la parte de la institución universitaria que se dedicaba al estudio del Derecho a la hora de suministrar materiales para el diagnóstico, pronóstico $\mathrm{y}$, sobre todo, superación, de la crisis enorme que, en su conjunto, aquellos acontecimientos conformaban. 
En este sentido, es este un libro de historia de las ideas jurídicas. Son estas lo que reciben en él una especial atención y lo que, principalmente, se reconstruye. Lo que ocurre es que la atención que presta el autor a las interacciones entre el pensamiento, la Universidad, los cambios sociales y las normas jurídicas le lleva a tratar con esas ideas no en el cielo abstracto de las intenciones puras, sino en el suelo concreto en el cual forman parte de la vida de los hombres. Es eso lo que le permite ir dotando de sentido a los acontecimientos, conceptos y promulgaciones legales de los que trata de manera que, en la realidad histórica compleja y trágica que configuran, puedan quedar enmarcadas y ser comprendidas las aportaciones de ciertos profesores a la misma.

Resulta esto evidente cuando nos fijamos en el índice del libro o, simplemente, cuando leemos el primer párrafo de la introducción, el cual nos avisa de que, no siendo lo que sigue una mera exposición de doctrinas y pensamientos, ni tampoco una relación de biografías, aspira a ordenarse como una "trama" general en la que las transformaciones sociales y políticas se entrecrucen con las reorientaciones del pensamiento, con las críticas y propuestas teóricas, con la apertura de nuevos horizontes y, en último término, con las trayectorias personales y académicas de aquellos que participaron en ellas.

Relacionar todo eso, lidiar con un sistema vivo de pensamientos, es pues lo que pretende este libro, cuyo autor se enfrenta a su tema directamente, a porta gaiola, ya en el primer capítulo, el titulado "La crisis del parlamentarismo liberal en el periodo de entreguerras en la Europa continental. Aproximación a las historias nacionales", consagrado a presentarnos el telón de fondo ante el cual se va a desarrollar la trama. Se trata aquí de situarnos. De tomar nota de las muchas sacudidas que el sistema parlamentario heredado del siglo anterior experimentó en los albores del siglo XX, la época de la irrupción de un nuevo mundo político, de la llamada sociedad de masas y de la segunda revolución industrial. Son sacudidas que recorrieron la Alemania vencida en la Gran Guerra, la Francia que durante la III República vio crecer fenómenos como la Action Française, la Italia en la que llegó al poder Mussolini o la España de la dictadura de Primo de Rivera y el Portugal del Estado Novo de António de Oliveira Salazar. Si el autor limita el escenario a estas naciones no procede así porque no haya equivalente en otras latitudes (por ejemplo, en los EE.UU. de la gran depresión), sino porque es bien consciente de que lo que quiere examinar es la crisis de una determinada tradición. 
Se ve esto muy bien en el siguiente capítulo, el titulado "Las transformaciones sociales. La democracia de masas y su impacto en los círculos académicos". En él el foco se concentra ya en una parte muy concreta de la tradición que entraba en crisis, aquella cuya aportación a la crisis es, además, lo que el libro está interesado en examinar. Pues, para el autor, fue entre determinados círculos universitarios, los cuales, desde su condición de aristocracia del saber y de élite meritocrática reaccionaron muy a su manera ante lo que pudo ser descrito, y de hecho lo fue, como "la rebelión de las masas", de donde acabarían surgiendo aquellas ideas relacionadas con "la formación del Derecho público en Europa" de las que ha prometido tratar en el título.

Preparadas dichas contribuciones por los trabajos previos de la Ciencia Social desde Comte hasta Gustave Le Bon, por lo que se dio en llamar la "revuelta antiformalista", o por aportaciones tan originales como las de Sigmund Freud, todas las cuales sacudieron a placer el discurso moral heredado de la Ilustración, Esteve se centra en las proporcionadas desde las universidades alemanas. En aquellos momentos las más importantes de Europa, sus profesores de Derecho Público, por razones obvias, se sintieron directamente interpelados por una crisis del sistema político que encontraba en su país, con Estados Unidos el corazón de la segunda revolución industrial, uno de sus escenarios preferidos.

Después de estos dos primeros capítulos tenemos ya en las tablas al protagonista, por lo que la trama anunciada puede empezar a desplegarse. Es lo que comienza a hacerse en el tercer capítulo, el que lleva por título "Los elementos de referencia y señas de identidad del pensamiento antiparlamentario", el cual atiende a la comprensión de la crisis por parte de un discurso que es universitario, técnico y sofisticado, y cuya primera reacción consiste en articular ideas, teorías y propuestas que, encontrando un precedente inmediato en autores como Maurice Hauriou, acabarían alumbrando, en su conjunto, y de acuerdo con la tesis de este libro, una renovación espectacular del Derecho público sin precedentes desde la Revolución Francesa.

Es este discurso especializado, jurídico, germánico y cultivado, tan atento a los tiempos que corren como influyente en la posteridad, discurso propio de quienes recibían en sus aulas y seminarios a profesores de toda Europa (entre los españoles, a Fernando de los Ríos, Francisco Ayala, Manuel García Pelayo, Javier Conde, Recaséns Siches, Wenceslao Roces o Legaz Lacambra) al que, a partir de ahora, le toca actuar. 
Sostenido por voces como las de Rudolf Smend, Eric Kaufmann, Hans Kelsen, Gerhard Leibholz, Carl Schmitt, Herman Heller, Ernst Forthoff o Heinrich Triepel, es el genuino protagonista del libro.

Sobre su intento de dar una respuesta vanguardista a la crisis planea, a su vez, la viejísima, eterna, disputadísima cuestión acerca de los límites de la disponibilidad legal del poder soberano. Así que Esteve, después de situar a su protagonista en su tiempo convulso y de ponerlo en la misma tesitura que Antígona, puede limitarse a dejarlo actuar. Es lo que va a hacer en los capítulos que restan: el cuarto, titulado sucintamente "La crítica"; el quinto, "Las aportaciones"; y el sexto y último, que lleva por título, también lacónico, el de "La transmisión de las ideas y las realizaciones".

El primero de ellos, el consagrado a la "crítica", pretende concentrarse en lo que de "anti" tiene ese pensamiento "anti-parlamentario". Toca en consecuencia pasar revista en él al cuestionamiento por parte de la doctrina académica de los presupuestos de aquel Estado liberal decimonónico en el cual el parlamento decidió asumir el papel de Creonte, convirtiéndose en "el legislador". Tienen esas críticas que ver con la denuncia de los rasgos tan claramente oligárquicos de aquel Estado, de su concepción tan abstracta de los derechos, así como de los diversos mitos que quiso asociar a su idea de democracia representativa. Críticas generalizadas pero que tuvieron su epicentro en Alemania, y de las cuales un muy buen representante fue Carl Schmitt, Esteve nos explica cómo su formulación fue bien consciente de las realidades sociales que rodeaban a los procesos electorales, de las muchas insuficiencias de una teoría política a la que le sobraba metafísica y le faltaba compasión, así como de los agujeros de una teoría jurídica empeñada en encumbrar a la Ley parlamentaria como la hija más perfecta del maridaje entre la razón y la soberanía.

Ahora bien, para el autor, el pensamiento antiparlamentario que está analizando no fue solo "anti". Hasta puede que ni siquiera fuera genuinamente "anti". Por eso, el libro no se queda en el análisis de las críticas, y se siente obligado a avanzar. Uno de los componentes de su trama, recordemos, es digno de una tragedia de Calderón. Por eso, el capítulo que sigue está dedicado a las “aportaciones”. En ellas se toma nota de la contribución que aquella doctrina hizo a la evolución del drama de las limitaciones del poder. Se trata de las diversas propuestas de cambios legales y constitucionales que, tras constatar las deficiencias del legislador parlamentario, algunos de aquellos profesores decidieron aportar, en un movimiento suyo que, en definitiva, no deja de ser otra cosa que el cumplimiento completo de su misión. 
Pasa entonces el libro a revisar las sugerencias de reforma del sistema parlamentario (en tanto que "reformas", ya solo, en cierto sentido, "antiparlamentarias") presentadas durante el periodo estudiado. Con antecedentes en el pensamiento institucionalista o en el vitalismo de Bergson, tienen que ver con la recomposición de un espacio cerrado a la intervención del legislador que recupere, de alguna forma, el desaparecido dualismo monarca-parlamento característico del estado decimonónico. Por esta orientación caminan, por ejemplo, el impulso de leyes dictadas por el gobierno, o Decretos-leyes, la formulación de la teoría de las relaciones especiales de sujeción, o la de las potestades normativas de la Administración. También la propuesta de mecanismos que facilitasen la vinculación del legislador a través de la aceptación de fórmulas como la concepción objetiva de los derechos fundamentales, los mandatos constitucionales o las garantías institucionales. O la de una recomposición de la arquitectura constitucional que se relaciona con la idea de superioridad de la Constitución en tanto que norma jurídica, las transformaciones del Derecho administrativo en sentido intervencionista, la introducción de Tribunales constitucionales y hasta con cosas como el exilio del Derecho constitucional en el Derecho Administrativo (fenómeno transitorio que, en nuestro país, se manifestó legalmente en ciertas realizaciones de Laureano López Rodó).

Decía Chéjov que, si en el primer acto de una obra aparece un arma, esta debe ser utilizada en algún momento. El autor de este libro sabe esto, y también que la rememoración del pasado ha de someterse siempre a un juicio de relevancia. Por eso dedica el capítulo sexto, y último, a una evaluación de resultados que se concentra en el asunto de qué sobrevivió, y qué no sobrevivió, de aquellos conceptos, ideas, doctrinas, mecanismos y fórmulas que han transitado a lo largo de la obra.

No ignora al hacer esto que, en este caso, esa supervivencia ha de ser buscada teniendo en cuenta la finalización brusca en 1945, y por inmensa y criminal catástrofe con epicentro también en Alemania, del periodo analizado. Tampoco que, tras la Guerra, muchos de los pensadores citados, así como muchos de sus pensamientos, tuvieron que hacer frente a responsabilidades más que graves. No quita esto que deje de notar que, y a pesar de que, sobre todo en los primeros momentos, la voluntad explícita fue de profunda ruptura, sea posible reconstruir el vínculo que une entre sí a Weimar y Bonn. Tenue al principio, Esteve subraya el papel que jugó en él Gerhard Leibholz, discípulo de Triepel que había tenido que exiliarse en Oxford por su condición de judío y al que se llamó para que formase parte del Tribunal Constitucional recién creado. Su labor, así como las presencias en la Ley Fundamental de Bonn (1949) de una 
concepción institucionalista de los derechos fundamentales que está detrás de cosas como la vinculación del legislador a unos contenidos dados y la referencia a un contenido esencial de tales derechos, contribuyó, de acuerdo con el autor, a que pueda afirmarse que, "discretamente", sin prisas, y a pesar de los pesares, la herencia de Weimar pudiera ir "envolviendo y abrazando" la Ley Fundamental de Bonn, la doctrina iuspublicista y la jurisprudencia del Tribunal Constitucional en tanto que algo que, resistiéndose a morir, fundamentó y sugirió las líneas de avance del Derecho público.

No se olvida el autor, al lado de tomar nota de lo que ha sobrevivido, de apuntar a lo que no lo hizo: las fórmulas parlamentarias corporativistas de democracia orgánica, por ejemplo. Tampoco que mucho de lo que sobrevivió llegó a España a través de la Constitución de 1978 y, en particular, de su diseño de los derechos fundamentales. Ello nos permite entender la manera en la que, por más que, a mediados de los años setenta, Schmitt lamentara que sus nietos españoles, los cuales desconocían bastante el alemán, viajaran a aprender inglés a Estados Unidos, se acabara asumiendo, a pesar de todo, cierto legado. Se fuera o no bien consciente de él, sobrevoló el ambiente cuando el presidente Suárez anunció, en 1977, que se iba a hacer la Constitución de "tipo europeo" que, finalmente, se hizo.

Lo que se reconstruye en este libro no es pues tanto un espejo como una tradición intelectual. Una genealogía de ciertos conceptos e instituciones, algo que no es nunca tan rectilíneo ni tan simple como muchos, acostumbrados a meter a Locke hasta en la sopa, parecen creer. A lo que responde el trabajo de su autor es a la comprensible, y a menudo valiente, pretensión de no simplificar. De ponerse a averiguar de dónde vienen realmente las cosas, en la confianza de que saber cómo hemos llegado hasta aquí ayuda a hacer frente a otra cuestión mucho más peliaguda: la de cómo saldremos de esta.

Es en este sentido básico en el que importa la historia. No para reconocernos en ella, pues siempre podremos reconocernos en cualquier reconstrucción de cosas humanas con sentido, sino para situarnos en nuestra realidad. El Derecho es una cosa histórica y, por eso, referirse a su historia es siempre poner un pie en su realidad. Ahora bien, el Derecho está también estrechamente ligado a algunos mitos, por lo que referirse a ellos será también acercarse a su realidad. Uno de los más persistentes ha sido el de la Democracia, y de lo que habla Esteve es de una crisis del Estado democrático. Una más. ¿Y cuándo no lo ha estado? Porque lo que pasa es que los mitos son variados y, al lado del de la democracia (ique 
mande el pueblo!, ;que mandemos todos!), está el del control de los abusos del poder (¡que no se arramble con todo!, ique se respete lo respetable!). Y ambos han tenido siempre que convivir.

Al autor de este libro, como al Derecho, como a los juristas, como a todos los seres humanos, le gustan los mitos. En 2020 ha publicado en Marcial Pons otro libro, Hay jueces en Berlín. Un cuento sobre el control judicial del poder, dedicado a un sucedido "no-sucedido" especialmente persistente que involucra a Federico de Prusia, a un molinero y al control judicial del poder.

Pero en El pensamiento antiparlamentario y la formación del Derecho público en Europa la cosa no va de mitos. O no tanto. Lo que encontramos en él es realidad pasada que se las arregla para llegar a ser realidad presente. Una crisis de primera categoría; unas propuestas teóricas (Germania docet) entre las que hay de todo; y una correa de transmisión que trae algunas de ellas hasta el presente. Lo que en él se reconstruye, a través de la combinación de biografías, acciones, conceptos, ideas, instituciones y normas, es continuidad intelectual.

La búsqueda de continuidades no está muy de moda en estos tiempos de inglés, innovación, transferencia, corrección política y atención a lo inmediato. Sin embargo, nada más útil para los que trabajan en la Universidad. Ello no solo porque les ayuda a no enfrentarse desnudos a los mitos, siempre, como Sísifo, empeñados en volver a empezar, sino porque les permite no comportarse ingenuamente, bárbaramente, ante la realidad, tan pronto pasando por encima de ella sin verla, tan pronto perdiéndose en minucias que reclaman el mérito de ser el último grito de la actualidad.

Por eso es bueno que se publiquen libros como este, que nos recuerda algo tan simple como que, en aquella espectacular crisis, hubo profesores en la Universidad, y que, pese a todo, también los hay en la actualidad. 